Article

\title{
High-Strength Konjac Glucomannan/Silver Nanowires Composite Films with Antibacterial Properties
}

\author{
Jia Lei ${ }^{1}$, Lei Zhou ${ }^{1}$, Yongjian Tang ${ }^{1}$, Yong Luo ${ }^{2}$, Tao Duan ${ }^{1,3, *}$ and Wenkun Zhu ${ }^{1,3, *}$ \\ 1 Sichuan Civil-Military Integration Institute, Mianyang 621010, China; cutiancheng@163.com (J.L.); \\ 18281605998@163.com (L.Z.); yjtang@swust.edu.cn (Y.T.) \\ 2 Sichuan Biotech Force Technology Co., Ltd., Mianyang 621010, China; kaientelo@gmail.com \\ 3 School of National Defense Science and Technology, Southwest University of Science and Technology, \\ Mianyang 621010, China \\ * Correspondence: duant@ustc.edu.cn (T.D.); zhuwk0@163.com (W.Z.); \\ Tel.: +86-816-608-9881 (T.D.); +86-816-608-9883 (W.Z.)
}

Academic Editor: Jun-ichi Anzai

Received: 15 March 2017; Accepted: 9 May 2017; Published: 12 May 2017

\begin{abstract}
Robust, high-strength and environmentally friendly antibacterial composite films were prepared by simply blending konjac glucomannan (KGM) and silver nanowires (Ag NWs) in an aqueous system. The samples were then characterized using scanning electron microscopy (SEM), X-ray diffraction (XRD), thermal gravimetric analysis, mechanical property tests, Fourier transform infrared spectra (FT-IR), X-ray photoelectron spectroscopy (XPS) and antimicrobial tests. The results showed that there was a high ratio of Ag NWs uniformly distributed in the composite films, which was vital for mechanical reinforcement and stable antibacterial properties. The enhanced thermal stability and mechanical intensity increased, while the elongation at break was reduced with an increase in the amount of Ag NWs found in the composite films. When the percentage of Ag NWs in the composite films reached 5\%, the tensile strength was $148.21 \mathrm{MPa}$, Young's modulus was $13.79 \mathrm{GPa}$ and the ultimate strain was $25.28 \%$. Antibacterial tests showed that the KGM films had no antibacterial effect. After the addition of Ag NWs, the composite films had an obvious inhibitory effect on bacteria, with the uniform dispersion of Ag NWs promoting the antibacterial effect to a certain degree. These results indicated that these composite films would have a potential application in the fields of environmentally friendly packaging or medicine.
\end{abstract}

Keywords: konjac glucomannan; silver nanowires; film; high strength; antimicrobial activity

\section{Introduction}

At present, most composite films are made of petroleum chemical polymers [1], which places an enormous amount of pressure on energy resources and the environment. It is reasonable to use natural polymers instead of petroleum products to save the non-renewable fossil fuels. In past decades, considerable attention has been given to investigating the new applications of natural polymers. A number of natural polymers and their derivatives were widely used as new functional materials in biochemical, industrial, medical and controlled-release fields. Konjac glucomannan (KGM), consisting of $\beta-1,4$ linked D-mannose and D-glucose, is a naturally renewable polysaccharide polymer from the tuber of the Amorphophallus konjac plant [2]. Generally, KGM has biodegradability [3], hydrophilicity [4], gel properties [5], film-forming ability [6,7], low caloric value, some special physiological functions and qualifiable functionalization [8]. KGM and KGM derivatives could be widely used in food, medicine, chemical and biological fields [9]. 
Although KGM has a variety of properties, pure KGM film has only a single function. To expand the applications of KGM films, nanotechnology has provided a new way for the preparation of composite materials with superior properties that may exceed the individual components [10]. Inorganic nanomaterial was introduced into KGM for organic/inorganic nanocomposites, as the small size effect of nanomaterials and the interaction between the matrices of the composite materials would improve the strength, stiffness, toughness and certain functionalities of the composite material [11,12]. However, the inorganic components in the polymer/inorganic nanocomposite films are mostly nanoparticles [13,14]. These nanoparticles can endow the material with their corresponding functional properties [15], which has little effect on the mechanical properties of the composite films. For one-dimensional metallic nanomaterials, especially for nanowires, the network structure can be formed in the polymer, which can improve the mechanical properties and provide the functional properties of the original material [16,17].

One-dimensional nanomaterials, such as silver nanowires (Ag NWs), prepared by template and template-free methods, have attracted great attention from electronic and chemistry researchers for their unique and controllable chemical, plasmonics, optical, beneficial catalytic properties and other related properties [18,19]. In addition, they can be used in electronics [20], catalysis, medicine, energy, information storage areas and so on. Recently, focus has been placed on fabricating Ag NW-related composites, due to their unique structure and nature [21,22], mechanical properties, antibacterial properties $[23,24]$ and the biocompatibility of Ag NWs potentially being transferred to the composite materials. Some polymers, such as polyvinyl alcohol, chitosan and resins, have been used as substrates for the Ag NWs to achieve high-strength antibacterial properties and chemical stability. However, there have been no reports of Ag NWs being added to the natural polymer konjac glucomannan for composite films.

In this present study, we fabricated a robust and antibacterial composite film by simply blending KGM and Ag NWs in an aqueous system, with Ag NWs being uniformly distributed in the composite film. Experiments on the syntheses, morphology, composition and structure, thermal stability, mechanical properties, rheological property and antibacterial property were also carried out. This composite film showed good thermostability, mechanical performance and antibacterial properties due to the unique character of the nanocomposites, which may show a promising application in the fields of environmentally friendly packaging and medicine.

\section{Materials and Methods}

\subsection{Materials}

Purified KGM was purchased from the Enshi Hongye Konjac Development Co., Ltd. (Enshi, China). Silver nitrate $\left(\mathrm{AgNO}_{3}\right)$ was purchased from the PLA 9509 factory (Wuhan, China). Polyvinyl-pyrrolidone (PVP) was purchased from the Regent Tianjin Chemical Co., Ltd. (Tianjin, China). Ethylene glycol $\left(\left(\mathrm{CH}_{2} \mathrm{OH}\right)_{2}\right)$ was purchased from the Tianjin Fu Yu Fine Chemical Co., Ltd. (Tianjin, China). Acetone $\left(\mathrm{CH}_{3} \mathrm{COCH}_{3}\right)$ was purchased from the Nanjing Chemical Reagent Co., Ltd. (Nanjing, China). Absolute ethyl alcohol $\left(\mathrm{C}_{2} \mathrm{H}_{6} \mathrm{O}\right)$ was purchased from the Tianjin Chemical Reagent Factory (Tianjin, China). Tris $\left(\mathrm{NH}_{2} \mathrm{C}\left(\mathrm{CH}_{2} \mathrm{OH}\right)_{3}\right)$ was purchased from the Sinopharm Chemical Reagent Factory (Shanghai, China). Hydrochloric acid $(\mathrm{HCl})$ was purchased from the Chengdu Kelong Chemical Reagent Factory (Chengdu, China).

\subsection{Synthesis of $A g N W s$}

$\mathrm{Ag}$ NWs were prepared using a solvothermal method [25]. A total of $10 \mathrm{~mL}$ of the PVP- $\left(\mathrm{CH}_{2} \mathrm{OH}\right)_{2}$ solution $(0.5 \mathrm{~mol} / \mathrm{L})$ was added to a $50-\mathrm{mL}$ three-necked flask, before being uniformly mixed and heated in an oil bath at $150{ }^{\circ} \mathrm{C}$ for $1.5 \mathrm{~h}$. A total of $10 \mathrm{~mL}$ of the $\mathrm{AgNO}_{3}-\left(\mathrm{CH}_{2} \mathrm{OH}\right)_{2}$ solution $(0.2 \mathrm{~mol} / \mathrm{L})$ was added to the three-necked flask, with heating stopped after $1 \mathrm{~h}$ of reaction time. Throughout the reaction, the rotor speed was $1200 \mathrm{rpm}$. The color of the reacting solution gradually changed from 
bright yellow to orange, before finally becoming pale. $\mathrm{CH}_{3} \mathrm{COCH}_{3}$ was added into the reaction solution twice, before undergoing ultrasonic washes. Following this, the resulting product was placed in the centrifuge at $5000 \mathrm{rpm}$ for $30 \mathrm{~min}$. After the upper section of the solution was discarded, the precipitate was dispersed in 95\% anhydrous ethanol to obtain the final Ag NWs sample.

\subsection{Synthesis of Composite Film}

The $0 \%, 1 \%, 2.5 \%$ and 5\% (w/w) Ag NWs were dispersed in $50 \mathrm{~mL}$ of distilled water and $1 \%$ $(\mathrm{w} / \mathrm{w}) \mathrm{KGM}$ was dissolved in the solution of Ag NWs by constantly stirring for $0.5 \mathrm{~h}$ in a water bath at $60{ }^{\circ} \mathrm{C}$. Next, the mixed solution was poured into a Petri dish before being vacuum-dried at $60^{\circ} \mathrm{C}$ for $12 \mathrm{~h}$. The dried composite films were immersed in a $2 \%(\mathrm{v} / \mathrm{v})$ sodium hydroxide ethanol solution at $65{ }^{\circ} \mathrm{C}$ for $5 \mathrm{~h}$. Following this, the films were removed, washed with water until neutral and then air-dried in a sterilization station at $60{ }^{\circ} \mathrm{C}$ for $12 \mathrm{~h}$ to obtain the dry composite films. The dried films were placed into a desiccator with $57 \%$ relative humidity (saturated solution of sodium bromide) for use. The schematic diagram of the production process of the composite film is shown in Figure 1a.
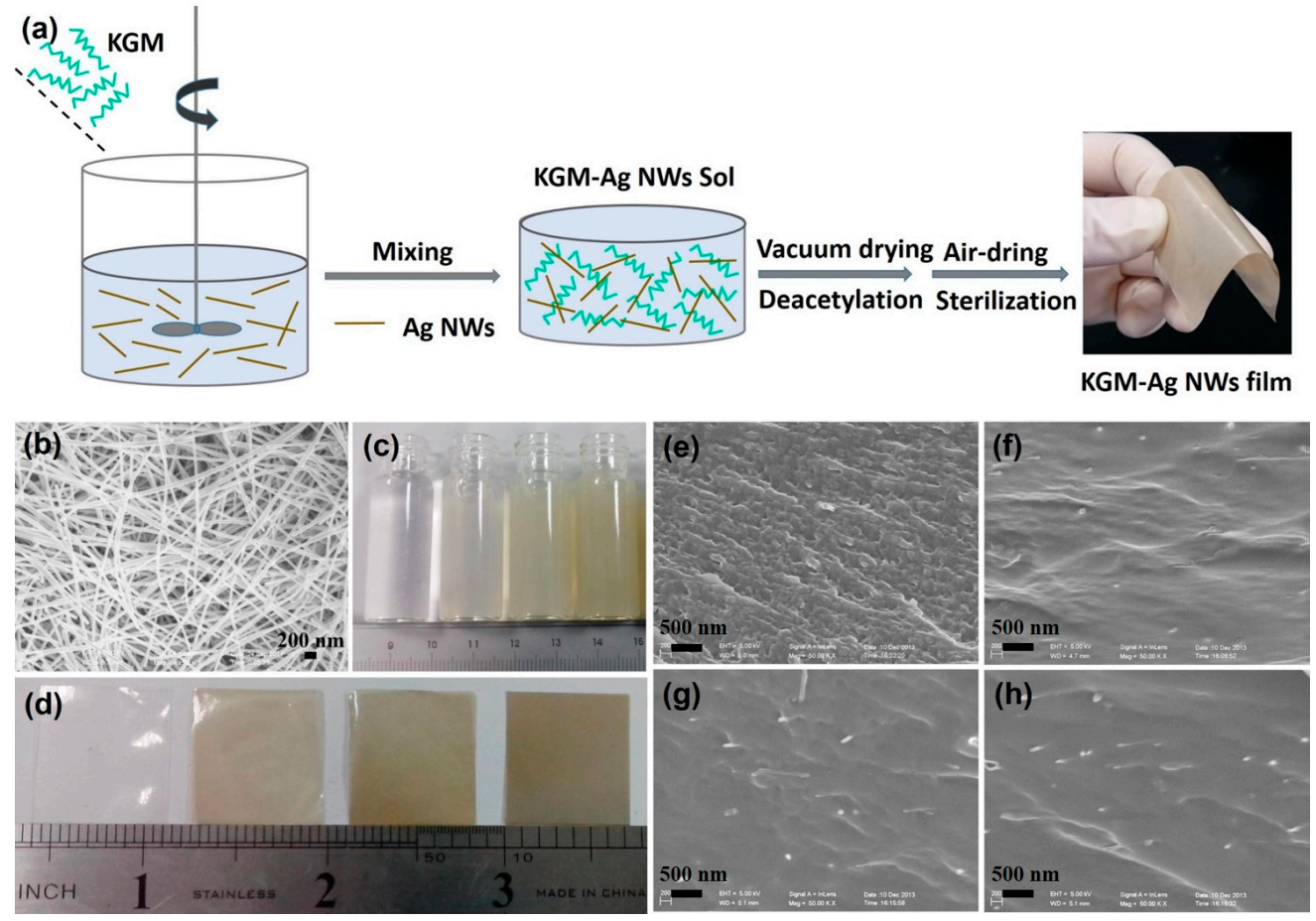

Figure 1. (a) Schematic representation for synthesis of hybrid film; (b) scanning electron microscopy (SEM) images of Ag NWs; photos of the KGM and composite (c) solutions; (d) films with increasing $\%$ wt of Ag NWs; cross-sectional SEM images of (e) KGM film; (f) KGM-Ag NWs-1\%; (g) KGM-Ag NWs-2.5\%; and (h) KGM-Ag NWs-5\% composite films.

\subsection{Characterization}

Film thickness was measured using a Vernier caliper with a standard error of \pm 0.01 from five different points, with the mean used in the calculation. Water content was calculated by weighing the films before and after drying at $60^{\circ} \mathrm{C}$. Transparency was measured by UV spectrophotometry (UV-2450, SHIMADZU, Tokyo, Japan). Water vapor permeability (WVP) tests were conducted following the ASTM (1981a) Method E96-80, with some modifications [26]. Scanning electron microscopy (JSM-6390/LV, Jeol, Tokyo, Japan) was utilized to characterize the structure of Ag NWs and the cross-sections of films, with the samples then being fractured in liquid nitrogen. X-ray diffraction (X Pert pro, PANalytical, Almelo, The Netherlands) patterns of the films were carried out with $\mathrm{CuK}(\alpha)$ 
radiation at a voltage of $60 \mathrm{kV}$ and a current of $50 \mathrm{~mA}$. Thermal gravimetric analyses (TGA) was carried out using a thermal gravimetric analysis instrument (Q5000, TA, Newark, NJ, USA) under nitrogen at a heating rate of $10{ }^{\circ} \mathrm{C} / \mathrm{min}$. The mechanical properties of films were measured by a static mechanical tester (Instron 5565A, INSTRON, Shanghai, China) under the tensile mode. During the measurement of the mechanical properties, the distance between the two fixtures equaled $5 \mathrm{~mm}$, the moving speed was $10 \mathrm{~mm} / \mathrm{min}$ and the films were cut into $23 \mathrm{~mm} \times 5 \mathrm{~mm}$ (length $\times$ width) rectangles before testing. X-ray photoelectron spectroscopy (XPS) analyses were carried out using a Kratos Axis Ultra (Kratos Analytical, Kratos Tech, Manchester, UK) photoelectron spectrometer. This instrument uses a monochromatic $\mathrm{Al} \mathrm{K}_{\alpha}$ X-ray source. Fourier transform infrared spectroscopy (FT-IR) spectra of films were taken by a Nicolet Avatar 370 FT-IR spectrometer (Thermo Nicolet, Waltham, MA, USA) at wavelength range of $4000-400 \mathrm{~cm}^{-1}$. Rheological analysis was measured by a HAAKE RS6000 Rotational Rheometer (Thermo Hakke, Hamburg, Germany). For this analysis, the frequency sweep was conducted from 0.01 to $100 \mathrm{rad} / \mathrm{s}$, with the 1-mm plate geometry rotor at $25 \pm 0.05{ }^{\circ} \mathrm{C}$ and a deformation of $0.5 \%$, which was within the linear viscoelastic range (LVE).

\subsection{Antimicrobial Tests}

The sterilized agar nutrient solution was melted and kept at $50{ }^{\circ} \mathrm{C}$ for $0.5 \mathrm{~h}$. Next, the solution was poured onto a sterile disposable petri dish, before being cooled and solidified. A total of $100 \mu \mathrm{L}$ of the overnight culture of E. coli and S. aureus $\left(10^{6} \mathrm{CFU} / \mathrm{mL}\right)$ was spread evenly across the plates, before the composite films and the KGM film were carefully placed in the medium containing E. coli. After the overnight incubation at $37^{\circ} \mathrm{C}$, the size of the inhibition zone was observed.

\section{Results and Discussion}

\subsection{Basic Information}

We controlled for the thickness of the KGM film and all KGM/Ag NWs films, which were all found to have relatively rough film surfaces. The film thickness and water content also did not show any significant differences between the KGM film and KGM/Ag NWs films. As shown in Table 1, the transparency of the KGM film was 85\%, with the transparency of films decreasing sharply with an increase in the concentration of Ag NWs. When the concentration of Ag NWs was 5\%, the transparency was 3\%, making it almost impossible to pass light through these films. The water vapor permeability rate of the film showed a similar trend. The water vapor permeability of the KGM film was $1.36 \times 10^{14} \mathrm{Kg} \mathrm{Pa}^{-1} \mathrm{~s}^{-1} \mathrm{~m}^{-1}$, which was reduced to $0.3 \times 10^{14} \mathrm{Kg} \mathrm{Pa}^{-1} \mathrm{~s}^{-1} \mathrm{~m}^{-1}$ when the concentration of $\mathrm{Ag}$ NWs was 5\%. This was due to the production of a large number of $\mathrm{Ag}$ NWs after the composite films were created. Figure $1 \mathrm{~b}$ depicts the typical SEM images of Ag NWs, demonstrating the successful fabrication of Ag NWs by the chemical reduction method. The Ag NWs had a uniform linear shape with a high aspect ratio of about 1300 . The diameter of the Ag NWs was about 30-40 $\mathrm{nm}$ and the length was more than $50 \mu \mathrm{m}$. Figure 1c,d show KGM and KGM/Ag NWs composite solutions and films, respectively. The images show that the KGM film was colorless and transparent. As the amount of Ag NWs increased, the color of the solution and films gradually increased, eventually becoming opaque. In addition, the composite KGM/Ag NWs films exhibited flexibility and could be bent naturally. Figure 1e shows the cross-sectional image of the KGM film, while Figure $1 \mathrm{f}-\mathrm{h}$ are cross-sectional SEM images of the composite films with different concentrations of Ag NWs. The cross-sectional surface of the KGM film was rough, while buried silver nanowires were obvious in the composite films with an increase in their concentration. The cross-sectional surface of the composite films was smooth, because the addition of Ag NWs made the films more compact. 
Table 1. Thickness, transparency, water vapor permeability and water content of Konjac glucomannan (KGM) and hybrid films with different concentrations.

\begin{tabular}{|c|c|c|c|c|}
\hline Samples & $\begin{array}{l}\text { Thickness } \\
\text { (mm) }\end{array}$ & $\begin{array}{c}\text { Transparency } \\
\text { (\%) }\end{array}$ & $\begin{array}{c}\text { WVP } \times 10^{14} \\
\left(\mathrm{Kg} \mathrm{Pa}^{-1} \mathrm{~s}^{-1} \mathrm{~m}^{-1}\right)\end{array}$ & $\begin{array}{c}\text { Water Content } \\
(\%)\end{array}$ \\
\hline KGM & $0.16 \pm 0.01$ & $85 \pm 0.8$ & $1.36 \pm 0.19$ & $0.21 \pm 0.06$ \\
\hline KGM-Ag NWs-1\% & $0.17 \pm 0.02$ & $43 \pm 0.5$ & $1.16 \pm 0.25$ & $0.19 \pm 0.07$ \\
\hline KGM-Ag NWs-2.5\% & $0.19 \pm 0.02$ & $20 \pm 0.6$ & $0.8 \pm 0.17$ & $0.18 \pm 0.05$ \\
\hline KGM-Ag NWs-5\% & $0.20 \pm 0.03$ & $3 \pm 0.2$ & $0.3 \pm 0.04$ & $0.16 \pm 0.03$ \\
\hline
\end{tabular}

\subsection{X-ray Diffraction (XRD) and Thermal Gravimetric Analysis}

Figure 2a shows the XRD patterns of the KGM-Ag NWs-5\% composite film, which uses the KGM film as the control sample. The XRD spectra of the KGM film had no obvious diffraction peaks, due to the low crystallinity. As for the KGM-Ag NWs- $5 \%$ composite film, four peaks at $2 \theta=38.1^{\circ}, 44.4^{\circ}$, $64.4^{\circ}$ and $77.5^{\circ}$ are presented, which correspond sequentially to the (111), (200), (220) and (311) of silver, which is consistent with the Joint Committee On Powder Diffraction Standards (JCPDS) file (No. 89-3722) [27].

Figure $2 \mathrm{~b}$ shows the TGA data of the KGM film and the KGM-Ag NWs-5\% composite film. As shown in Figure 2b, the thermal decomposition of the KGM film was divided into two stages [28]. The first stage ranges from 38 to $175^{\circ} \mathrm{C}$, corresponding with a weight loss of $7.25 \%$. This weight loss was due to the loss of free water and part of the combined water, due to the absorption of water in the $-\mathrm{OH}$ and non-crystalline regions. The second stage was from 175 to $354{ }^{\circ} \mathrm{C}$. This was the process of degradation and cracking of the polymer chain. The rate of weight loss was the fastest in this process, with the weight loss being $74.21 \%$. From 354 to $700{ }^{\circ} \mathrm{C}$, the remaining residue of $\mathrm{KGM}$ was carbon-black in color and its corresponding content was about $17.21 \%$. When Ag NWs were added, the decomposition of the composite film in the first stage was significantly delayed at $208{ }^{\circ} \mathrm{C}$. The rate of weight loss slowed down, but the weight loss did not change significantly. In the second stage without adding silver nanowires, weight loss decreased to $11.62 \%$. Finally, the residue was $22.84 \%$. The data showed that the thermal stability of the composite film was increased by adding Ag NWs. This was probably due to the Ag NWs forming a reticular structure between KGM molecules and acting as the crosslinking point in the composite films, which control thermal motions of the polymer matrix in the composite film [29].
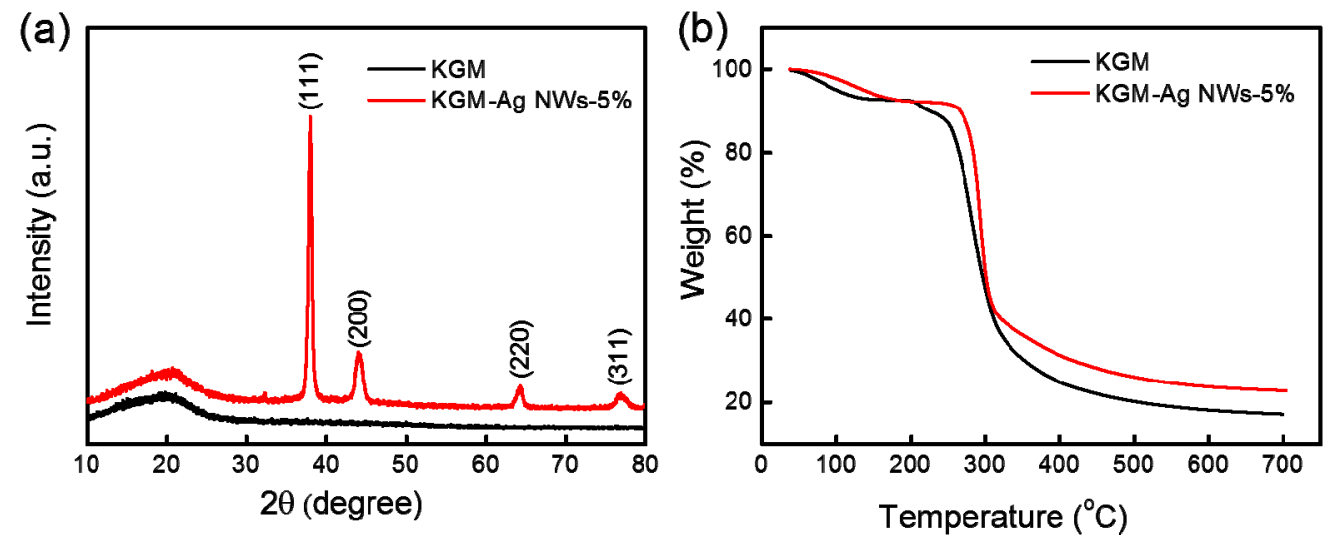

Figure 2. (a) X-ray diffraction (XRD) patterns for the KGM film and the KGM-Ag NWs-5\% composite film; (b) Thermal gravimetric analyses (TGA) results of the KGM film and the KGM-Ag NWs-5\% composite film. 


\subsection{Mechanical Performance}

The mechanical properties of the composite film were enhanced with the addition of the Ag NWs. The stress-strain curves of the KGM film and the KGM/Ag NWs films are shown in Figure 3a. The tensile strength of the pure KGM film was $81.9 \mathrm{MPa}$ and the strain was $37.4 \%$. When the content of the Ag NWs was 1\%, the tensile strength increased by $40 \%$. However, the strain of the composite film did not change. With an increase in the tensile strength, the strain on the composite film became smaller. When the content of the Ag NWs was 5\%, the tensile strength increased by $85 \%$ to reach a maximum of $148.21 \mathrm{MPa}$, while the strain decreased by $32 \%$. This showed that a small amount of silver nanowires $(\sim 1 \%)$ had no effect on the flexibility of the film. However, continuously adding silver nanowires could reduce the flexibility of the composite film.

The dependence of Young's modulus and the ultimate strain on the content of Ag NWs for composite films are shown in Figure 3b. Young's modulus of the KGM film was $6.67 \mathrm{GPa}$, and the ultimate strain was $38.05 \%$. Young's modulus of the KGM/Ag NWs film with 5\% of Ag NWs was $13.79 \mathrm{GPa}$ and the ultimate strain was $25.28 \%$. Results show that Young's modulus of the composite film increased with the addition of Ag NWs, but the ultimate strain was reduced. Ag NWs in the $\mathrm{KGM} / \mathrm{Ag}$ NWs films can improve the mechanical properties in a similar way to how other flakes or inorganic fibers improve the mechanical properties in reinforced polymers [30]. It is well-understood that Ag NWs prepared by the polyol process have a high tensile strength [31], which can reinforce the KGM/Ag NWs films when breaking occurs. Ag NWs played a significant reinforcement effect, which restricted the growth of the KGM matrix and Ag NWs in addition to resulting in beneficial tensile properties. It is apparent that the Ag NWs forming network structures can suppress crack propagation in the KGM films and generate a more uniform strength.
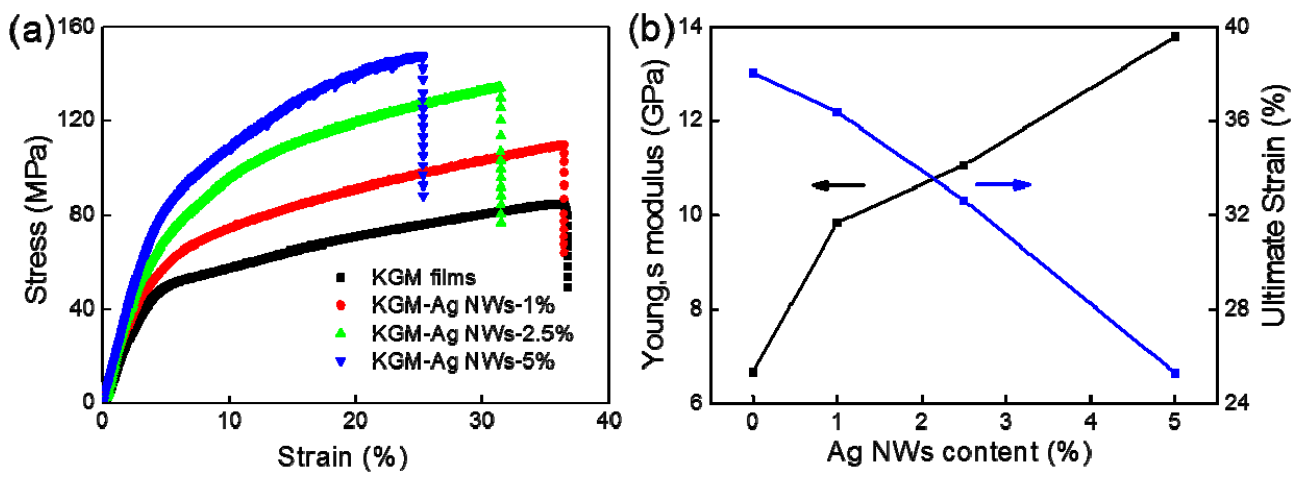

Figure 3. (a) The stress-strain curves of the KGM film and the KGM/Ag NWs films; (b) the dependence of Young's modulus and the ultimate strain on the content of Ag NWs for composite films.

\subsection{FT-IR Analysis}

The FT-IR spectra of the KGM and KGM-Ag NWs-5\% films with a wavelength range of $4000-400 \mathrm{~cm}^{-1}$ is shown in Figure 4. The absorption bands at $3431 \mathrm{~cm}^{-1}$ and the peaks at $2923 \mathrm{~cm}^{-1}$ of KGM were assigned to the stretching of $-\mathrm{OH}$ groups and $\mathrm{C}-\mathrm{H}$ of methyl in KGM. The absorption bands at 1729,1637 and $1050 \mathrm{~cm}^{-1}$ were assigned to the stretching of $\mathrm{C}=\mathrm{O}, \mathrm{C}-\mathrm{O}$, and $\mathrm{C}-\mathrm{O}-\mathrm{H}$ groups. The absorption bands at 881 and $810 \mathrm{~cm}^{-1}$ were characteristic vibrations of the mannose unit in KGM. By comparing the spectra of KGM and KGM-Ag NWs-5\% film, the -OH and C-O-H stretching peaks moved to the high wavelengths of $3435 \mathrm{~cm}^{-1}$ and $1055 \mathrm{~cm}^{-1}$, respectively, which was due to the damage of hydrogen bonding from the hydration between the KGM molecular chain and the water molecule in alkaline solutions [32,33]. Thus, this implies an interaction between the -OH groups of KGM and the Ag NWs in the KGM-Ag NWs-5\% films [34]. The existence of these interactions in the assembly films would further explain the resultant mechanical reinforcement effect. 


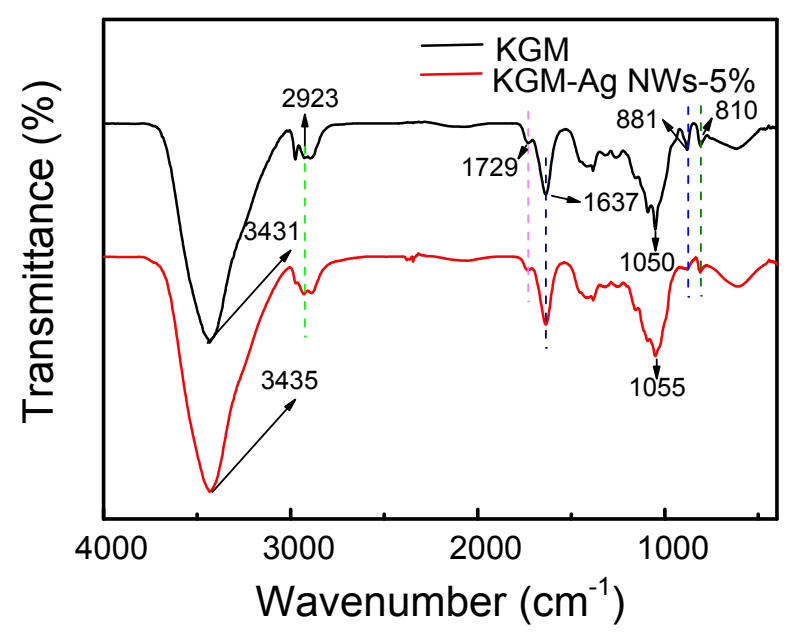

Figure 4. Fourier transform infrared spectroscopy (FT-IR) spectrum of the KGM and KGM-Ag NWs-5\% films.

\subsection{Rheological Analysis}

Figure 5a depicts the changes in storage $\left(\mathrm{G}^{\prime}\right)$ and loss modulus $\left(\mathrm{G}^{\prime \prime}\right)$ in the frequency sweep of the KGM solution and KGM/Ag NWs solution. Under the same concentration of KGM, $\mathrm{G}^{\prime}$ and $\mathrm{G}^{\prime \prime}$ all increased gradually with the increase of Ag NWs, which illustrated that the interaction between Ag NWs and KGM has been enhanced. Ag NWs between the KGM polyhydroxy substances formed complex bridges, which increased the interaction forces between molecular chains. Figure $5 \mathrm{~b}$ depicts the statistics regarding the intersection modulus and crossover frequency in different amounts of $\mathrm{Ag}$ NWs. With an increasing concentration of $\mathrm{Ag}$ NWs, the intersection modulus of $\mathrm{G}$ was increased up to a maximum of $50 \%$ higher. However, the crossover frequency was decreased by about $40 \%$. This means that it had higher mechanical properties, which could resist at a lower frequency and for a longer time. This was due to the polyhydroxy of KGM and Ag NWs. The density of molecular chains was obviously improved, with an increase in the crosslinking point and entanglement of molecular chains.
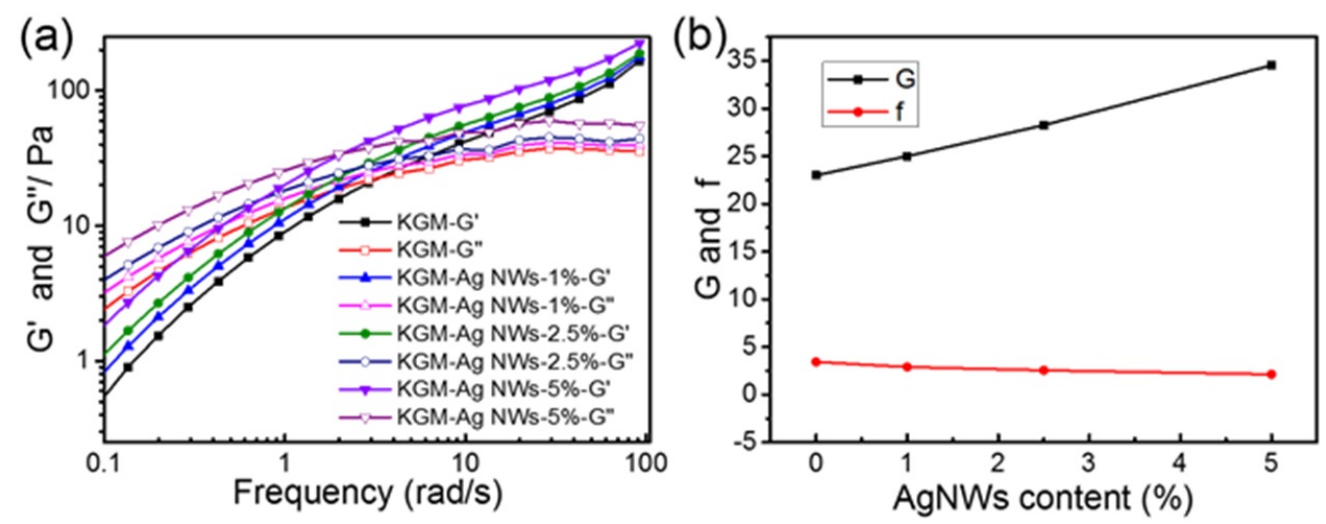

Figure 5. (a) The frequency sweep of KGM solution and KGM/Ag NWs solution; (b) statistics on the intersection modulus and crossover frequency in different amounts of Ag NWs.

\subsection{XPS Analysis}

XPS was used to analyze the chemical functionalities and covalent bonds in the KGM/Ag NWs film. The survey spectrum showed the presence of $\mathrm{C}, \mathrm{O}$ and Ag elements (Figure 6a). The high resolution of the C1s XPS spectra was shown in Figure 6b. There were four fitting peaks in the C1s curve, including $\mathrm{C}-\mathrm{C} / \mathrm{C}-\mathrm{H}(284.5 \mathrm{eV}), \mathrm{C}-\mathrm{OH}(285.8 \mathrm{eV}), \mathrm{C}-\mathrm{O}-\mathrm{C}(287.1 \mathrm{eV})$ and $\mathrm{C}=\mathrm{O}(288.2 \mathrm{eV})$. 
The O1s peak (Figure 6c) fit into two components and the peaks indicated two different types of oxygen linkages. The lower binding energy $(531.3 \mathrm{eV})$ stands for oxygen (labeled as O1) bonded to carbon in a double bond $(\mathrm{C}=\mathrm{O})$, while the higher one (labeled as $\mathrm{O} 2)(532.4 \mathrm{eV})$ was produced by the $\mathrm{C}-\mathrm{O}$ bond. As shown in Figure 6d, the appearance of two peaks centered at $367.9 \mathrm{eV}$ and $373.9 \mathrm{eV}$ were assigned to $\mathrm{Ag} 3 \mathrm{~d}_{5 / 2}$ and $\mathrm{Ag} 3 \mathrm{~d}_{3 / 2}$, respectively, revealing that the $\mathrm{Ag} \mathrm{NWs}$ were in the metallic state in the KGM/Ag NWs composite film.
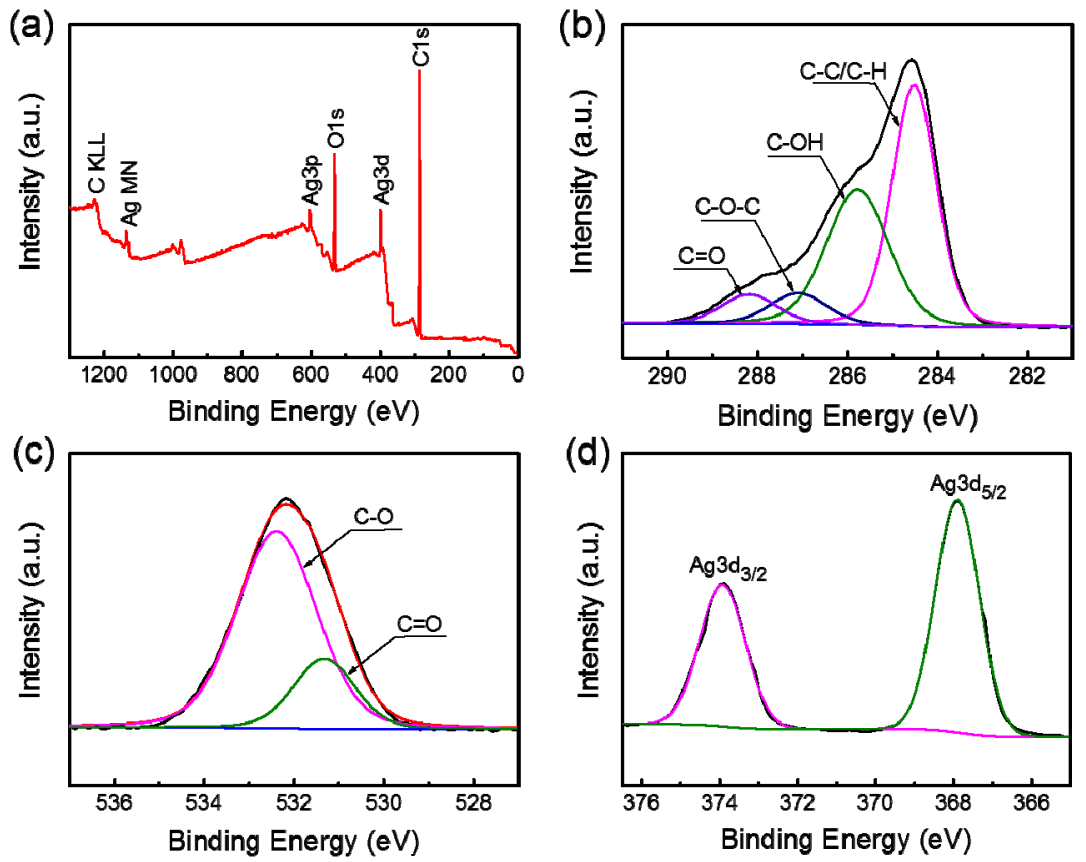

Figure 6. (a) XPS spectrum of the KGM-Ag NWs-5\% composite film; high-resolution spectra of samples for the elements of (b) C, (c) O and (d) Ag.

\subsection{Antimicrobial Tests}

It is common knowledge that nanoparticles of silver have excellent antimicrobial activity. However, in previous studies, the antimicrobial activity of Ag NWs was rarely reported. For example, Shahzadi et al. [30] reported a type of CS/Ag NWs film had a good antibacterial effect on E. coli and S. aureus. In this antifungal test, we found that there was no inhibition zone in the KGM antibacterial test (Figure 7a,e), which was consistent with the antimicrobial activity found for the pure KGM film in previous research [35]. However, the KGM solution has antimicrobial activity, while pure KGM films are not antimicrobial. In addition, the inhibition zone of E. coli and S. aureus gradually increased with increasing amounts of Ag NWs. The calculated average inhibition zones of $E$. coli were approximately $8.4,11.2$ and $14.6 \mathrm{~mm}$ (Figure $7 \mathrm{~b}-\mathrm{d}$ ), while these average zones were $9,13.6$ and $16 \mathrm{~mm}$ for S. aureus (Figure 7f-h). The nano-size and the large specific surface area of Ag NWs was beneficial for the adsorption of the bacterial cell membrane and combined with the enzyme thiol (-SH) involved in metabolism to inactivate this enzyme, resulting in a blockage of metabolism [36]. The dissolution of Ag NWs allowed these particles to enter the bacteria and produce an inhibitory effect. In addition, the uniform distribution of Ag NWs in the KGM film also promoted the antibacterial property of the composite film to a certain degree. 


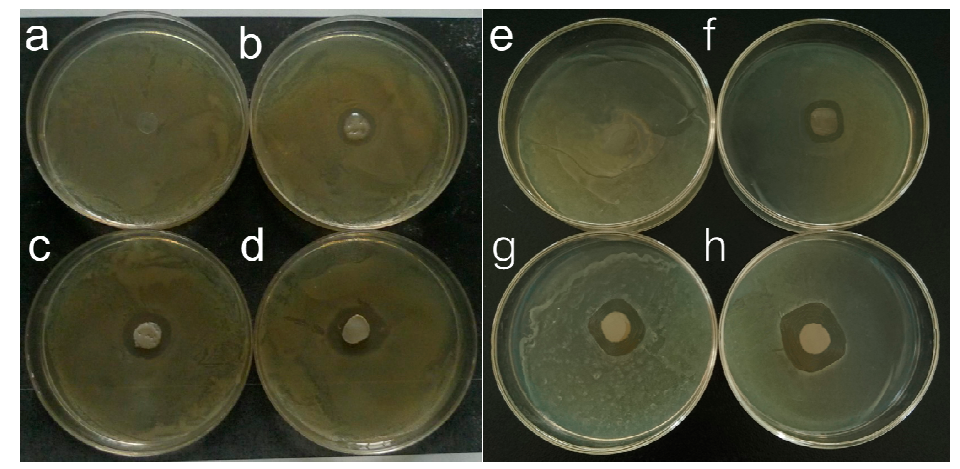

Figure 7. Photos of inhibitory zones for E. coli using the: (a) KGM film, (b) KGM-Ag NWs-1\% film, (c) KGM-Ag NWs-2.5\% film and (d) KGM-Ag NWs-5\% film; and for S. aureus using the: (e) KGM film, (f) KGM-Ag NWs-1\% film, (g) KGM-Ag NWs-2.5\% film and (h) KGM-Ag NWs-5\% film.

\section{Conclusions}

We fabricated robust and antibacterial composite films of KGM and Ag NWs, with Ag NWs uniformly distributed in the composite films. After the addition of Ag NWs, the tensile strength of the composite films was increased, while the strain was decreased. The weight loss of the composite film was lowered and the thermal stability of the composite film was improved. When the content of Ag NWs reached 5\%, the tensile strength was $148.21 \mathrm{MPa}$ and Young's modulus was $13.79 \mathrm{GPa}$. The KGM film had no antibacterial effect. After the addition of Ag NWs, the composite films had an obvious bacterial inhibitory effect and the uniform dispersion of Ag NWs promoted the antibacterial effect to a certain degree. We predict that this high-strength KGM/Ag NWs composite film would have potential applications as environmentally friendly packaging or in medicine in the future.

Acknowledgments: This work was financially supported by Postgraduate Innovation Fund Project by Southwest University of Science and Technology (No. 16ycx005), Projects in the Sichuan Province Science \& Technology Pillar Program (No. 2016GZ0259, 2016GZ0277 and 2014GZ0185), Key research and development project of science and technology department of Sichuan province(No. 2017GZ0342), National Natural Science Foundation of China (No. 21601147 and 21406182), Doctoral Research Fund Project of Southwest University of Science and Technology (No. 15zx7130), Project 201410619024 supported by Sichuan's Training Program of Innovation and Entrepreneurship for Undergraduate, 2015 Mianyang City Yongquan Endeavour Team (No. 2015YQFII-2), and Mianyang Science and Technology Type Small and Medium-sized Enterprise Innovation Fund (No. 15MLCL003).

Author Contributions: Jia Lei, Wenkun Zhu and Tao Duan conceived and designed the study; Jia Lei and Lei Zhou performed the experiments; Yongjian Tang and Yong Luo analyzed the data; Jia Lei and Wenkun Zhu wrote the majority of the paper and all authors reviewed and approved the final version.

Conflicts of Interest: The authors declare no conflict of interest.

\section{References}

1. Lau, W.J.; Ismail, A.F.; Misdan, N.; Kassim, M.A. A recent progress in thin film composite membrane: A review. Desalination 2012, 287, 190-199. [CrossRef]

2. Wang, Q.; Wang, J.; Zhong, G. Characteristics of konjac glucomannan (kgm) in a.Bulbifer compared with that in a.Rivieri and a.Albus. Adv. Mater. Res. 2011, 236-238, 2045-2052. [CrossRef]

3. Mikkonen, K.S.; Tenkanen, M. Sustainable food-packaging materials based on future biorefinery products: Xylans and mannans. Trends Food Sci. Technol. 2012, 28, 90-102. [CrossRef]

4. Ding, C.C.; Zhang, M.; Li, G.Y. Preparation and characterization of collagen/hydroxypropyl methylcellulose (hpmc) blend film. Carbohydr. Polym. 2015, 119, 194-201. [CrossRef] [PubMed]

5. Zhang, T.; Xue, Y.; Li, Z.J.; Wang, Y.M.; Xue, C.H. Effects of deacetylation of konjac glucomannan on alaska pollock surimi gels subjected to high-temperature (120 degrees c) treatment. Food Hydrocoll. 2015, 43, 125-131. [CrossRef] 
6. Yu, Z.J.; Jiang, Y.Q.; Zou, W.W.; Duan, J.J.; Xiong, X.P. Preparation and characterization of cellulose and konjac glucomannan blend film from ionic liquid. J. Polym. Sci. Part B Polym. Phys. 2009, 47, 1686-1694. [CrossRef]

7. Huang, Y.C.; Yang, C.Y.; Chu, H.W.; Wu, W.C.; Tsai, J.S. Effect of alkali on konjac glucomannan film and its application on wound healing. Cellulose 2015, 22, 737-747. [CrossRef]

8. Xiao, M.; Dai, S.H.; Wang, L.; Ni, X.W.; Yan, W.L.; Fang, Y.P.; Corke, H.; Jiang, F.T. Carboxymethyl modification of konjac glucomannan affects water binding properties. Carbohydr. Polym. 2015, 130, 1-8. [CrossRef] [PubMed]

9. Duan, J.C.; Lu, Q.; Chen, R.W.; Duan, Y.Q.; Wang, L.F.; Gao, L.; Pan, S.Y. Synthesis of a novel flocculant on the basis of crosslinked konjac glucomannan-graft-polyacrylamide-co-sodium xanthate and its application in removal of $\mathrm{Cu}^{2+}$ ion. Carbohydr. Polym. 2010, 80, 436-441. [CrossRef]

10. Zhang, H.; Gu, C.H.; Wu, H.; Fan, L.; Li, F.; Yang, F.; Yang, Q. Immobilization of derivatized dextran nanoparticles on konjac glucomannan/chitosan film as a novel wound dressing. Biofactors 2007, 30, 227-240. [CrossRef] [PubMed]

11. Fernandez, J.G.; Ingber, D.E. Unexpected strength and toughness in chitosan-fibroin laminates inspired by insect cuticle. Adv. Mater. 2012, 24, 480-484. [CrossRef] [PubMed]

12. Bonderer, L.J.; Studart, A.R.; Gauckler, L.J. Bioinspired design and assembly of platelet reinforced polymer films. Science 2008, 319, 1069-1073. [CrossRef] [PubMed]

13. Francis, R.; Joy, N.; Aparna, E.P.; Vijayan, R. Polymer grafted inorganic nanoparticles, preparation, properties, and applications: A review. Polym. Rev. 2014, 54, 268-347. [CrossRef]

14. Hanemann, T.; Szabo, D.V. Polymer-nanoparticle composites: From synthesis to modern applications. Materials 2010, 3, 3468-3517. [CrossRef]

15. Zhang, F.Y.; Zhou, Y.M.; Cao, Y.; Chen, J. Preparation and characterization of kgm/cds nanocomposite film with low infrared emissivity. Mater. Lett. 2007, 61, 4811-4814. [CrossRef]

16. Wu, J.H.; Zang, J.F.; Rathmell, A.R.; Zhao, X.H.; Wiley, B.J. Reversible sliding in networks of nanowires. Nano Lett. 2013, 13, 2381-2386. [CrossRef] [PubMed]

17. Lee, H.; Kim, I.; Kim, M.; Lee, H. Moving beyond flexible to stretchable conductive electrodes using metal nanowires and graphenes. Nanoscale 2016, 8, 1789-1822. [CrossRef] [PubMed]

18. Wang, J.; Jiu, J.T.; Nogi, M.; Sugahara, T.; Nagao, S.; Koga, H.; He, P.; Suganuma, K. A highly sensitive and flexible pressure sensor with electrodes and elastomeric interlayer containing silver nanowires. Nanoscale 2015, 7, 2926-2932. [CrossRef] [PubMed]

19. Kwak, W.J.; Jung, H.G.; Lee, S.H.; Park, J.B.; Aurbach, D.; Sun, Y.K. Silver nanowires as catalytic cathodes for stabilizing lithium-oxygen batteries. J. Power Sources 2016, 311, 49-56. [CrossRef]

20. Lopez-Diaz, D.; Merino, C.; Velazquez, M.M. Modulating the optoelectronic properties of silver nanowires films: Effect of capping agent and deposition technique. Materials 2015, 8, 7622-7633. [CrossRef]

21. Zeng, X.Y.; Zhang, Q.K.; Yu, R.M.; Lu, C.Z. A new transparent conductor: Silver nanowire film buried at the surface of a transparent polymer. Adv. Mater. 2010, 22, 4484-4488. [CrossRef] [PubMed]

22. Gaynor, W.; Burkhard, G.F.; McGehee, M.D.; Peumans, P. Smooth nanowire/polymer composite transparent electrodes. Adv. Mater. 2011, 23, 2905-2910. [CrossRef] [PubMed]

23. Zhao, C.; Deng, B.; Chen, G.C.; Lei, B.; Hua, H.; Peng, H.L.; Yan, Z.M. Large-area chemical vapor deposition-grown monolayer graphene-wrapped silver nanowires for broad-spectrum and robust antimicrobial coating. Nano Res. 2016, 9, 963-973. [CrossRef]

24. Tang, C.L.; Sun, W.; Lu, J.M.; Yan, W. Role of the anions in the hydrothermally formed silver nanowires and their antibacterial property. J. Colloid Interface Sci. 2014, 416, 86-94. [CrossRef] [PubMed]

25. Khan, Z.; Hussain, J.I.; Kumar, S.; Hashmi, A.A. Silver nanoplates and nanowires by a simple chemical reduction method. Colloid Surf. B 2011, 86, 87-92. [CrossRef] [PubMed]

26. Cheng, L.H.; Abd Karim, A.; Seow, C.C. Characterisation of composite films made of konjac glucomannan (kgm), carboxymethyl cellulose (cmc) and lipid. Food Chem. 2008, 107, 411-418. [CrossRef]

27. Alsharaeh, E.H. Polystyrene-poly(methyl methacrylate) silver nanocomposites: Significant modification of the thermal and electrical properties by microwave irradiation. Materials 2016, 9, 458. [CrossRef]

28. Yu, H.Q.; Huang, Y.H.; Ying, H.; Xiao, C.B. Preparation and characterization of a quaternary ammonium derivative of konjac glucomannan. Carbohydr. Polym. 2007, 69, 29-40. [CrossRef] 
29. Tamboli, M.S.; Kulkarni, M.V.; Patil, R.H.; Gade, W.N.; Navale, S.C.; Kale, B.B. Nanowires of silver-polyaniline nanocomposite synthesized via in situ polymerization and its novel functionality as an antibacterial agent. Colloids Surf. B Biointerfaces 2012, 92, 35-41. [CrossRef] [PubMed]

30. Shahzadi, K.; Wu, L.; Ge, X.S.; Zhao, F.H.; Li, H.; Pang, S.P.; Jiang, Y.J.; Guan, J.; Mu, X.D. Preparation and characterization of bio-based hybrid film containing chitosan and silver nanowires. Carbohydr. Polym. 2016, 137, 732-738. [CrossRef] [PubMed]

31. Yang, C.; Gu, H.; Lin, W.; Yuen, M.M.; Wong, C.P.; Xiong, M.; Gao, B. Silver nanowires: From scalable synthesis to recyclable foldable electronics. Adv. Mater. 2011, 23, 3052-3056. [CrossRef] [PubMed]

32. Huang, L.; Takahashi, R.; Kobayashi, S.; Kawase, T.; Nishinari, K. Gelation behavior of native and acetylated konjac glucomannan. Biomacromolecules 2002, 3, 1296-1303. [CrossRef] [PubMed]

33. Zhang, H.; Yoshimura, M.; Nishinari, K.; Williams, M.A.; Foster, T.J.; Norton, I.T. Gelation behaviour of konjac glucomannan with different molecular weights. Biopolymers 2001, 59, 38-50. [CrossRef]

34. Tian, D.; Hu, W.; Zheng, Z.; Liu, H.; Xie, H.-Q. Study on in situ synthesis of konjac glucomannan/silver nanocomposites via photochemical reduction. J. Appl. Polym. Sci. 2006, 100, 1323-1327. [CrossRef]

35. Du, X.Z.; Yang, L.X.; Ye, X.; Li, B. Antibacterial activity of konjac glucomannan/chitosan blend films and their irradiation-modified counterparts. Carbohydr. Polym. 2013, 92, 1302-1307. [CrossRef] [PubMed]

36. Fan, L.; Zhu, H.; Zheng, H.; Xu, Y.; Zhang, C. Structure and properties of blend fibers prepared from alginate and konjac glucomannan. J. Appl. Polym. Sci. 2007, 106, 3903-3907. [CrossRef]

(C) 2017 by the authors. Licensee MDPI, Basel, Switzerland. This article is an open access article distributed under the terms and conditions of the Creative Commons Attribution (CC BY) license (http://creativecommons.org/licenses/by/4.0/). 